\title{
Magnesium in Chronic Kidney Disease: Unanswered Questions
}

\author{
David M. Spiegel \\ University of Colorado Denver, Denver, Colo., USA.
}

\section{Key Words}

Magnesium • Chronic kidney disease - End-stage renal disease $\cdot$ Phosphate binder - Vascular calcification .

Cardiovascular disease

\begin{abstract}
Background: Magnesium ion is critical for life and is integrally involved in cellular function and a key component of normal bone mineral. In health, the kidneys, gastrointestinal tract and bone are responsible for maintaining serum magnesium concentrations in the normal range and magnesium balance. Most clinical disorders involving magnesium, other than chronic kidney disease (CKD), result in hypomagnesemia, either from gastrointestinal or kidney losses. CKD and particularly end-stage kidney disease is the only clinical condition where sustained hypermagnesemia may occur and net magnesium balance may be positive. Methods: This review will focus on normal magnesium homeostasis and review the literature in CKD with a particular focus on endstage kidney disease and the potential role of magnesium as a phosphate binder and in cardiovascular and bone health. Results: A number of small to medium-size interventional trials have shown that magnesium-based compounds can serve as effective phosphate binders. Observational studies suggest that higher serum magnesium concentrations in dialysis patients may improve survival and may slow the pro-
\end{abstract}

\section{KARGER}

Fax +4161306 1234 E-Mail karger@karger.ch www.karger.com
(C) 2011 S. Karger AG, Basel

0253-5068/11/0313-0172\$38.00/0

Accessible online at:

www.karger.com/bpu gression of vascular calcification. While a few small prospective trials support these findings, no large or long-term studies are available. Conclusions: Magnesium balance remains poorly understood in patients with end-stage kidney disease. While observational and small randomized trials suggest that exogenous administration may be useful as a phosphate binder and may have protective cardiovascular effects in terms of both arrhythmias and vascular calcification, large randomized trials are needed to test these hypotheses.

Copyright $\odot 2011$ S. Karger AG, Basel

\section{Normal Magnesium Homeostasis}

The gastrointestinal tract, the skeleton, and the kidneys are integrally involved in normal magnesium homeostasis. Gastrointestinal absorption is not highly regulated, and the kidneys play the primary role in maintaining balance. Bone plays an important role as a buffer, providing a large rapidly exchangeable pool to protect against acute changes in serum concentrations, although this has not been as well studied as in calcium regulation. Principal dietary sources of magnesium include green vegetables, seafood, meats, grains and nuts [1]. The understanding of normal magnesium physiology has been greatly increased by the discovery of mutations in specific magnesium transporters, most of which lead to de-
David M. Spiegel, MD

University of Colorado Denver

4545 E 9 th Ave, Suite 160

Denver, CO 80220 (USA)

Tel. +1 303399 6997, Fax +1 303399 3131, E-Mail david.spiegel@ ucdenver.edu 
creased gastrointestinal magnesium absorption or kidney magnesium wasting $[2,3]$. As a result, most clinical disorders of magnesium are due to magnesium deficiency and are predominately due to gastrointestinal or kidney losses. These disorders can be either hereditary or acquired. Chronic kidney disease (CKD), and especially end-stage kidney disease is the only clinical disorder that has the potential to cause sustained hypermagnesemia and net positive magnesium balance.

Serum magnesium concentrations can be reported as $\mathrm{mEq} / \mathrm{l}, \mathrm{mM}$ or $\mathrm{mg} / \mathrm{dl}$. One $\mathrm{mEq} / \mathrm{l}=0.5 \mathrm{mM}$ and is approximately $1.2 \mathrm{mg} / \mathrm{dl}$ [1]. The magnesium concentration in health is closely maintained within a normal range that varies between laboratories, but is roughly $1.50-2.3$ $\mathrm{mEq} / \mathrm{l}(1.8-2.8 \mathrm{mg} / \mathrm{dl})$. Only about $1-2 \%$ of total body magnesium is present in the extracellular fluid [4] of which about $20 \%$ is protein bound. The principal stores of the body's $21-28 \mathrm{~g}(1,750-2,400 \mathrm{mEq})$ of magnesium are bone (67\%) and muscle (20\%). Due to the distribution of magnesium and the fact that intracellular magnesium may not be readily exchangeable, serum concentrations do not adequately reflect total body stores.

\section{Magnesium Balance in CKD}

Stage 5 CKD patients on dialysis are generally felt to have elevated serum magnesium concentration and to be at risk for acute and chronic magnesium overload [5]. Gastrointestinal magnesium absorption is felt to be normal in patients with CKD, although one small study of 5 dialysis patients suggested it was decreased compared to normal controls, possibly due to low 1,25 dihydroxy-vitamin D levels [6]. The magnesium content of the dialysate is largely responsible for controlling magnesium balance in dialysis patients. Over the past 30 years, the dialysate magnesium concentration has changed very little, ranging from 0.35 to $0.75 \mathrm{mM}$ in the bicarbonate dialysis era and from 0 to $0.75 \mathrm{~mm}$ in the acetate dialysis era [7]. Patients dialyzed against a magnesium concentration of $0.75 \mathrm{~mm}(1.5 \mathrm{mEq} / \mathrm{l})$ demonstrated an increased postdialysis magnesium level of $2.32 \mathrm{mEq} / 1(2.78 \mathrm{mg} / \mathrm{dl}) \mathrm{com}$ pared to normal controls of $1.62 \mathrm{mEq} / \mathrm{l}(1.94 \mathrm{mg} / \mathrm{dl})$ [8]. A study evaluating pre- and postdialysis serum magnesium concentrations found that patients dialyzed against a $0.75 \mathrm{~mm}$ magnesium dialysate had a decrease in their serum magnesium concentrations from 2.38 to 2.20 $\mathrm{mEq} / \mathrm{l}$, although both values were above normal controls of $1.36 \mathrm{mEq} / \mathrm{l}$ [9]. A more recent study using high-efficiency dialysis and magnesium dialysate concentrations of $0.75,0.25$ and $0 \mathrm{mM}$ found that serum magnesium was unchanged on the 0.75 bath, decreased from 2.8 to 1.7 $\mathrm{mEq} / \mathrm{l}(3.4-2.1 \mathrm{mg} / \mathrm{dl})$ on the $0.25 \mathrm{bath}$, and decreased from 2.8 to $1.3 \mathrm{mEq} / \mathrm{l}(3.4-1.6 \mathrm{mg} / \mathrm{dl})$ on the $0 \mathrm{mM}$ bath. Net magnesium removal was calculated to be 56,306 , and $486 \mathrm{mg}$, respectively [10].

Overall, dialysis patients tend to have higher serum magnesium concentrations than controls. The serum concentrations are largely dependent on the dialysate composition unless the patient is ingesting excess magnesium. However, like all predominately intracellular ions, the serum magnesium concentration does not necessarily reflect total body balance.

\section{Magnesium as a Phosphate Binder}

Magnesium-based phosphate binders have been used since the mid-1980s and were initially introduced to replace aluminum-containing binders. Magnesium hydroxide use was complicated by diarrhea and mild hyperkalemia [11]. Magnesium carbonate $\left(\mathrm{MgCO}_{3}\right)$ proved more effective and resulted in fewer side effects. When substituted for aluminum hydroxide $\left(\mathrm{AlOH}_{3}\right)$, it provided equal control of phosphorus, without increases in serum magnesium. To achieve this goal, the investigators eliminated magnesium from the dialysate [12]. A combination of $\mathrm{MgCO}_{3}$ and calcium carbonate $\left(\mathrm{CaCO}_{3}\right)$ was used in 32 peritoneal dialysis patients, again using a magnesium free dialysate, and demonstrated equal phosphorus control over 1 year compared with $\mathrm{CaCO}_{3}$ or $\mathrm{AlOH}_{3}$. In a crossover-designed hemodialysis study, $\mathrm{MgCO}_{3}$ was added at a starting dose of $750 \mathrm{mg} /$ day (214 mg elemental magnesium) and $\mathrm{CaCO}_{3}$ was reduced by $50 \%$ [13]. The magnesium dose was uptitrated to achieve a phosphorus of $<6 \mathrm{mg} / \mathrm{dl}$. In this study, the dialysate magnesium was decreased from $0.75(1.5 \mathrm{mEq} / \mathrm{l})$ to $0.25 \mathrm{mM}(0.5 \mathrm{mEq} / \mathrm{l})$ during the period of magnesium administration. Overall, phosphorus was well controlled without an increase in serum magnesium concentrations. In a randomized trial of $\mathrm{MgCO}_{3} / \mathrm{CaCO}_{3}$ versus calcium acetate in hemodialysis patients on a standard $0.375 \mathrm{~mm}(0.75 \mathrm{mEq} / \mathrm{l})$ magnesium bath, phosphorus was equally controlled, while the net calcium ingestion was significantly less in the $\mathrm{MgCO}_{3}$ treated group [14]. The serum magnesium did increase in the magnesium-treated group, although it was well tolerated. In the largest study over 24 weeks, 204 patients completed a randomized trial of $\mathrm{MgCO}_{3} / \mathrm{Ca}$-acetate versus sevelamer hydrochloride. All patients were dialyzed against a $0.5 \mathrm{~mm}$ magnesium dialysate. Phosphorus con- 
trol was overall noninferior in the $\mathrm{MgCO}_{3}$ group [15]. Although the serum magnesium and calcium were slightly higher in the $\mathrm{MgCO}_{3} / \mathrm{Ca}$-acetate group, the medication was well tolerated without serious short-term adverse events. In a phase 2 trial of an iron-magnesium hydrocarbonate phosphate binder, 1 or $2 \mathrm{~g}$ three times a day with meals resulted in a statistically significant reduction in the serum phosphorus. The $1 \mathrm{~g}$ dose was well tolerated, while the $2 \mathrm{~g}$ dose resulted in a statistically higher number of adverse events resulting in drug discontinuation [16].

\section{Magnesium and Cardiovascular Health}

\section{General Population}

Cardiac arrhythmias are an important complication of magnesium depletion. Both extracellular and/or intracellular magnesium depletion has been implicated in a variety of cardiovascular disturbances including ventricular arrhy thmias, especially in patients on digitalis. Magnesium depletion has been associated with a prolonged QTc interval [17], whereas magnesium supplementation has been shown to reduce the QTc intervals even in patients with normal serum magnesium levels [18]. Magnesium depletion also has been implicated in the pathogenesis of torsades de pointes, an arrhythmic disorder that occurs in the presence of QT prolongation. Because of its ability to shorten the QT interval in some studies, magnesium supplementation has been used with some success in treating torsades de pointes [19]. Magnesium has also been shown to attenuate the electrophysiologic effects of hyperkalemia [20] and to control ventricular arrhythmias, including those induced by digitalis [21]. However, the clinical utility of magnesium in preventing cardiac arrhythmias is controversial. Two meta-analyses found that prophylactic magnesium administration decreased the incidence of postcardiothoracic surgery atrial fibrillation [22, 23], although the dose of administered magnesium varied widely among trials.

There also appears to be a direct effect of magnesium on the regulation of vascular tone and possibly atherogenesis. A small trial evaluating endothelial function and nitroglycerin-mediated vasodilatation found that oral administration of magnesium for a 6-month period improved flow-mediated vasodilatation and exercise tolerance in patients with stable coronary artery disease [24]. Patients in the active treatment arm received $365 \mathrm{mg}$ of elemental magnesium per day, and tissue levels, measured in sublingual epithelial cells, increased from below normal to within the normal range.

\section{Chronic Kidney Disease}

There are no data evaluating the effect of magnesium concentrations on cardiac arrhythmias in patients with end-stage kidney disease. Most literature in dialysis regarding magnesium relates to vascular reactivity and vascular calcification. Interest in magnesium in dialysis grew after several small retrospective studies showed that patients with higher serum magnesium concentrations had less progression of vascular calcification [25, 26]. A study in 44 peritoneal dialysis patients evaluated for progression of vascular calcification by fine detail radiographs of the hands and feet demonstrated that patients who did not progress had higher serum magnesium concentrations; 2.52 versus $2.24 \mathrm{mEq} / \mathrm{l}(3.0 \pm 0.5$ vs. $2.7 \pm 0.5 \mathrm{mg} / \mathrm{dl})$ than those who progressed [25]. There was no difference in calcium, phosphorus or PTH between groups. A study of 56 hemodialysis patients evaluated for valvular calcification by echocardiogram found that mitral annular calcification was more common in the subjects with serum magnesium concentrations $<2.5 \mathrm{mEq} / 1$ ( $3 \mathrm{mg} / \mathrm{dl})$ [26]. However, an observational study of 24 dialysis patients evaluated by repeat electron-beam computed tomography failed to show a difference in serum magnesium concentration in slow progressors versus rapid progressors [27]. The only prospective evaluation of vascular calcification in magnesium-supplemented dialysis patients was small and nonrandomized. Seven patients were treated with magnesium containing phosphate binders with a goal to elevate the serum magnesium concentration. Patients were evaluated by electron beam computed tomography at baseline, 6, 12 and 18 months for coronary artery and aortic calcification [28]. The authors found minimal progression over 18 months in these patients despite the presence of vascular calcification at study entry, a finding significantly different than reported in the literature for patients receiving calcium-based phosphate binders.

Two studies have evaluated carotid intima-media thickness and magnesium. An observational study of 93 hemodialysis patients showed an inverse correlation between both serum magnesium and intracellular magnesium and carotid intima-media thickness [29]. A short-term study (2 months) of magnesium-supplemented hemodialysis patients demonstrated a significant reduction in carotid intima-media thickness [30]. Finally, an observational study of 515 hemodialysis patients from Japan found an association of low magnesium and all-cause mortality even after adjustment for known confounders [31].

While these studies suggest a theoretical benefit for elevated magnesium levels in chronic dialysis patients at high risk for cardiac ischemia, arrhythmias, and death, 
to date there are no adequately powered randomized trials to confirm these preliminary findings.

\section{Magnesium and Bone Disease}

Bone is the predominate store of total body magnesium. The major portion of magnesium is complexed with apatite crystals in a ratio with calcium of 50:1 with calcium being the predominate cation [1]. It is estimated that about $20-30 \%$ of total bone magnesium exists as a surface-limited ion and therefore freely exchangeable with serum magnesium [32]. Bone magnesium content is felt to be the best indicator of total body magnesium stores. Early studies of bone magnesium content showed an increased magnesium in both cortical and trabecular bone in dialysis patients treated for 2 years on a $0.65 \mathrm{~mm}$ magnesium dialysate, suggesting increased total body magnesium stores [33]. A one-year follow-up bone histology study in 6 dialysis patients found a decrease in osteomalacia when the dialysate magnesium was decreased from 0.5 to $0.25 \mathrm{~mm}$ despite a high dialysate calcium of $1.75 \mathrm{~mm}$ [34]. A larger study analyzed 100 bone biopsies of end-stage renal disease (ESRD) patients with varying forms of renal osteodystrophy and found no significant increase in total bone magnesium compared to healthy controls, although the magnesium to calcium content of bone was increased in all forms of renal osteodystrophy [35]. Whether the abnormal magnesium to calcium ratio observed in the bone biopsy studies reflects increased total body magnesium content or disrupted magnesium or calcium incorporation into the bone mineral remains uncertain, as do the long-term clinical consequences. These somewhat conflicting data may be explained by changes in the management of mineral and bone disease including changes in phosphate binders and the use of active vitamin $\mathrm{D}$ and its analogues as well as changes in the di- alysis procedure itself over time. Clearly, bone serves as a source for magnesium release during times of magnesium depletion and as a sink for excess magnesium during magnesium loading, dampening the rise in serum levels under conditions of chronic exposure. More work is needed to understand the relationship between bone magnesium content, the bone disease associated with $\mathrm{CKD}$, and total body magnesium balance.

\section{Conclusions and Unanswered Questions}

Serum magnesium concentrations are sometimes increased in patients with ESRD. This presumably relates to relatively normal gastrointestinal absorption and impaired net kidney excretion. Magnesium balance in ESRD is largely dictated by the dialysate magnesium content. Unfortunately, serum magnesium concentrations do not reflect total body magnesium content and better determinates of total magnesium balance are not readily accessible nor have they been standardized.

Magnesium-based compounds have been shown to be effective phosphate binders. Newer formulations can achieve good phosphorus control with only small increases in the serum magnesium concentrations to levels that do not produce acute cardiovascular or neuromuscular symptoms. Observational and small prospective studies suggest that increased serum magnesium or magnesium supplementation may have beneficial effects on vascular health and even mortality without adverse effects on bone metabolism. However, no long-term adequately powered studies are available. With the high rate of cardiovascular mortality and sudden death in ESRD patients, the time seems right to begin to study the potential benefits of magnesium in this patient population.

\section{References}

1 Spiegel DM: Normal and abnormal magnesium metabolism; in Schrier RW (ed): Renal and Electrolyte Disorders, ed 7. Philadelphia, Lippincott Williams \& Wilkins, 2010, pp 229-250.

-2 Alexander RT, Hoenderop JG, Bindels RJ: Molecular determinants of magnesium homeostasis: insights from human disease. J Am Soc Nephrol 2008;19:1451-1458.

$\checkmark 3$ Naderi ASA, Reilly RF Jr: Hereditary etiologies of hypomagnesemia. Nat Clin Nephrol 2007;4:80-89.
4 Walser M: Magnesium metabolism. Ergeb Physiol 1967;59:185-296.

5 Cronin RE: Magnesium disorders; in Kokko JP, Tannen RL (eds): Fluid and Electrolytes. Philadelphia, WB Saunders, 1986, pp $502-$ 512.

-6 Brannan PG, Vergne-Marini P, Pak CYC, Hull AR, Fordtran JS: Magnesium absorption in the human small intestine: results in normal subjects, patients with chronic renal disease, and patients with absorptive hypercalciuria. J Clin Invest 1976;57:1412-1418.
7 Stewart WK: The composition of dialysis fluid; in Maher JF (ed): Replacement of Renal Function by Dialysis, ed 3. Dordrecht, Kluwer Academic Publishers, 1989, pp 199-217.

$\checkmark 8$ Pedrozzi NE, Truttmann AC, Faraone R, Descoeudres CE, Wermuth B, Luthy CM, Nuoffer JM, Frey FJ, Bianchetti MG: Circulating ionized and total magnesium in endstage kidney disease. Nephron 1998;79:288292 . 
-9 Truttmann AC, Faraone R, Von Vigier RO, Nuoffer JM, Pfister R, Bianchetti MG: Maintenance hemodialysis and circulating ionized magnesium. Nephron 2002;92:616-621.

$\checkmark 10$ Kelber J, Slatopolsky E, Delmez JA: Acute effects of different concentrations of dialysate magnesium during high-efficiency dialysis. Am J Kidney Dis 1994;24:453-460.

$\checkmark 11$ Guillot AP, Hood VL, Runge CF, Gennari FJ: The use of magnesium-containing phosphate binders in patients with end-stage renal disease on maintenance hemodialysis. Nephron 1982;30:114-117.

- 12 O’Donovan R, Baldwin D, Hammer M, Moniz C, Parsons V: Substitution of aluminium salts by magnesium salts in control of dialysis hyperphosphataemia. Lancet 1986; i:880-882.

13 Delmez JA, KelberJ, Norword KY, Giles KS, Slatopolsky E: Magnesium carbonate as a phosphate binder: a prospective, controlled, crossover study. Kidney Int 1996;49:163-167.

-14 Spiegel DM, Farmer B, Smits G, Chonchol M: Magnesium carbonate is an effective phosphate binder for chronic hemodialysis patients: a pilot study. J Ren Nutr 2007;17:416422 .

15 De Francisco AL, Leidig M, Covic AC, Ketteler M, Benedyk-Lorens E, Mircescu GM, Scholz C, Ponce P, Passlick-Deetjen J: Evaluation of calcium acetate/magnesium carbonate as a phosphate binder compared with sevelamer hydrochloride in haemodialysis patients: a controlled randomized study (CALMAG study) assessing efficacy and tolerability. Nephrol Dial Transplant DOI: $10.1093 /$ ndt/gfq292.

-16 McIntyre CW, Pai P, Warwick G, et al: Ironmagnesium hydroxycarbonate (fermagate): a novel non-calcium-containing phosphate binder for the treatment of hyperphosphatemia in chronic hemodialysis patients. Clin J Am Soc Nephrol 2009;4:401-409.

$\checkmark 17$ Sellig MS: Electrocardiographic patterns of magnesium depletion appearing in alcoholic heart disease. Ann NY Acad Sci 1969;162: 906-917.
8 Krasner BS, Girdwood R, Smith H: The effect of slow releasing oral magnesium chloride on the QTC interval of the electrocardiogram during open heart surgery. Can Anaesthesiol Soc J 1981;28:329-333.

19 Gupta A, Lawrence AT, Krishnan K, Kavinsky CJ, Trohman RG: Current concepts in the mechanisms and management of druginduced QT prolongation and torsade de pointes. Am Heart J 2007;153:891-899.

20 Kraft LE, Katholi RE, Woods WT, et al: Attenuation by magnesium of the electrophysiologic effects of hyperkalemia on human and canine heart cells. Am J Cardiol 1980;45 1189-1195.

21 Roden DA: Magnesium treatment of ventricular arrhythmias. Am J Cardiol 1989;63: 43G-46G.

22 Henyan N, Gillespie EL, White CM, Kluger J, Coleman CI: Impact of intravenous magnesium on post-cardiothoracic surgery atrial fibrillation and length of hospital stay: a meta-analysis. Ann Thorac Surg 2005;80:24022406.

23 Shiga T, Wajima Z, Inoue T, Ogawa R: Magnesium prophylaxis for arrhythmias after cardiac surgery: a meta-analysis of randomized controlled trials. Am J Med 2004;117: 325-333.

24 Shechter M, Sharir M, Labrador MJP, Forrester J, Silver B, Merz NB: Oral magnesium therapy improved endothelial function in patients with coronary artery disease. Circulation 2000;102:2353-2358.

25 Meema HE, Oreopoulos DG, Rapoport A: Serum magnesium level and arterial calcification in end-stage renal disease. Kidney Int 1987;32:388-394.

26 Tzanakis I, Pras A, Kounali D, Mamali V, Kartsonakis V, Mayopoulou-Symvoulidou D, Kallivretakis N: Mitral annular calcifications in haemodialysis patients: a possible protective role of magnesium. Nephrol Dial Transplant 1997;12:2036-2037.
27 Tamashiro M, Iseki K, Sunagawa O, Inoue T, Higa S, Afuso H, Fukiyama K: Significant association between the progression of coronary artery calcification and dyslipidemia in patients on chronic hemodialysis. Am J Kid Dis 2001;38:64-69.

28 Spiegel DM, Farmer B: Long-term effects of magnesium carbonate on coronary artery calcification and bone mineral density in hemodialysis patients: a pilot study. Hemodial Int 2009;13:453-459.

29 Tzanakis I, Virvidakis K, Tsomi A, Mantakas E, Girousis N, Karefyllakis N, Papadaki A, Kallivretakis N, Mountokalakis T: Intraand extracellular magnesium levels and atheromatosis in haemodialysis patients. Magnes Res 2004; 17:102-108.

-30 Turgut F, Kanbay M, Metin MR, Uz E, Akcay A, Covic A: Magnesium supplementation helps to improve carotid intima media thickness in patients on hemodialysis. Int Urol Nephrol 2008;40:1075-1082.

$>31$ Ishimura E, Okuno S, Tamakawa T, et al: Serum magnesium concentration is a significant predictor of mortality in maintenance hemodialysis patients. Mag Res 2007;20: 237-244.

32 Alfrey AC, Miller NL, Butkus D: Evaluation of body magnesium stores. J Lab Clin Med 1974;84:153-162.

33 Contiguglia SR, Alfrey AC, Miller N, Butkus D: Total-body magnesium excess in chronic renal failure. Lancet 1972;1:1300-1302.

34 Gonella M, Ballanti P, Rocca CD, Calabrese G, Pratesi G, Vagelli G, Mazzotta A, Bonucci E: Improved bone morphology by normalizing serum magnesium in chronically hemodialyzed patients. Miner Electrolyte Metab 1988;14:240-245.

35 D'Haese PC, Couttenye MM, Lamberts LV, et al: Aluminum, iron, lead, cadmium, copper, zinc, chromium, magnesium, strontium, and calcium content in bone of endstage renal failure patients. Clin Chem 1999; 45:1548-1556. 